\title{
Disiplin digital dan mediasi media oleh orang tua pada anak usia dini saat pandemi COVID-19
}

\author{
Hardiyanti Pratiwi* \& Nor Izzatil Hasanah \\ Program Studi Pendidikan Islam Anak Usia Dini, Fakultas Tarbiyah dan Keguruan, Universitas Islam \\ Negeri Antasari, Banjarmasin
}

\begin{abstract}
Abstrak
Intensitas penggunaan perangkat digital oleh anak usai dini saat pandemi COVID-19 meningkat. Mediasi media dan disiplin digital sangat diperlukan agar peningkatan akses tersebut diiringi dengan antisipasi atas konten negatif dan penguatan kesan konten positif. Penelitian deskriptif kualitatif ini bertujuan mengungkap bentuk disiplin digital dan mediasi media yang diterapkan orang tua pada penggunaan perangkat digital oleh anak usia dini saat penerapan kebijakan work and study from home. Hasil penelitian menunjukkan bahwa pola disiplin yang diterapkan oleh partisipan dalam penelitian ini ada tiga macam, yaitu: mengurangi intensitas dan durasi akses perangkat digital, memitigasi konten, dan mengombinasi keduanya. Pola disiplin tersebut dilakukan dengan beberapa strategi, yaitu: pengalihan aktivitas; pembatasan durasi atau situasi, penghambatan akses, dan pembiasaan. Adapun mediasi media yang paling banyak dan sering diterapkan oleh partisipan adalah tipe mediasi restriktif. Selain itu, ada juga yang mengombinasikan berbagai tipe mediasi, yaitu restriktif-co-viewing, teknikal-aktif, serta restriktif-aktif.
\end{abstract}

Kata kunci: Mediasi Media, Disiplin Digital, Perangkat Digital, Anak Usia Dini, COVID-19

\begin{abstract}
Children use digital devices at an early age when the COVID-19 pandemic is increasing. Media mediation and digital discipline are needed so that increased access is accompanied by anticipation of negative content and strengthening the impression of positive content. This qualitative descriptive study aims to reveal the form of digital discipline and media mediation that parents apply to the use of digital devices by early childhood when implementing the work and study from home policy. The results showed that there were 3 types of disciplinary patterns applied by the participants in this study, namely: reducing the intensity and duration of access to digital devices, mitigating content, and combining the two. The discipline pattern is carried out with several strategies, namely: shifting activities, duration or situation restrictions, inhibition of access, and habituation. Meanwhile, the most frequently used media mediation by participants is the type of restrictive mediation. In addition, there are also those that combine various types of mediation, namely restrictive-co-viewing, technical-active, as well as restrictive-active.
\end{abstract}

Keywords: Media Mediation, Digital Discipline, Digital Devices, Early Childhood, COVID-19

\section{Pendahuluan}

Riset tentang penggunaan perangkat digital oleh anak di Asia Tenggara yang dilakukan oleh Unantenne (2014) berhasil menghimpun data dari lima negara, yakni Singapura, Malaysia, Indonesia, Filipina dan Thailand dan menemukan bahwa sekitar 98\% (dari 2.714) orang tua memberikan izin kepada anaknya untuk menggunakan perangkat digital seperti komputer, smartphone dan tablet. Alasan yang mendasari keputusan orang tua tersebut adalah agar anaknya dapat mempergunakan perangkat digital sebagai media belajar. Pada prakteknya, anak-anak kemudian lebih banyak mengakses konten hiburan dari perangkat digital yang diberikan kepada mereka.

Meningkatnya aksesibilitas perangkat digital juga terjadi pada anak usia dini (Ofcom, 2014; Rideout, 2013; Unantenne, 2014). Hasil penelitian longitudinal yang dilakukan oleh Pemerintah Australia mengungkapkan bahwa mayoritas anak-anak di Australia menggunakan perangkat digital, hal ini tidak sesuai dengan rkomendasi pemerintah, dimana anak usia 18-24 bulan tidak disarankan menggunakan perangkat digital. Masa ini adalah periode perkembangan kritis, dimana mereka seharusnya didorong untuk sebanyak mungkin melakukan interaksi fisik. Sedangkan bagi anak umur 3-5 tahun,
Naskah masuk: 13 Mei 2020

Naskah diterima: 26 Mei 2021
* Fakultas Tarbiyah dan Keguruan, Universitas Islam Negeri Antasari Jl. Ahmad Yani Km. 4,5, Banjarmasin, Kalimantan Selatan E-mail: diyankonayuki@gmail.com 
diperbolehkan mengakses perangkat digital maksimal 1 jam per hari (Sweetser dkk., 2012). Studi terbaru juga mengemukakan bahwa terjadi peningkatan akses perangkat digital pada anak di masa pandemi COVID-19 (Pratiwi, 2020). Paparan teknologi digital ini mengubah cara anak belajar dan berinteraksi dengan yang lainnya (Wartella dkk., 2013). Sehingga selama masa pandemi, kegiatan belajar mengajar dilakukan secara jarak jauh dapat berdampak pada meningkatnya interaksi anak-anak pada layar, baik itu layar televisi, laptop, maupun smartphone.

Dalam membahas penggunaan media pada anak usia dini, faktor kontekstual yang relevan adalah mediasi media oleh orang tua. Peran ini dikonseptualisasikan sebagai praktik yang dilakukan orang tua untuk mengelola dan mengatur pengalaman anak-anak mereka dengan media. Peran manajemen dan mediasi penggunaan perangkat digital sangat urgen dan menentukan untuk meminimalisir dampak negatif (Clark, 2011). Sikap penggunaan perangkat digital orang tua merupakan salah satu prediktor paling kuat yang membentuk pola penggunaan perangkat digital anak-anak mereka (Cingel \& Krcmar, 2013; Lauricella, dkk., 2015). Sementara, banyaknya eksistensi perangkat digital di sekitar orang tua, baik dalam jumlah maupun intensitas penggunaannya, juga dapat berpengaruh terhadap persepsi dan kebiasaan penggunaan perangkat digital pada anak.

Beberapa penelitan yang berfokus pada proses dan pola mediasi orang tua hanya melihat interaksi anak dengan satu aktivitas mengakses perangkat digital, seperti menggunakan internet (Lee \& Chae, 2007), memainkan game (P Nikken \& Jansz, 2006), atau menggunakan media sosial (Shin \& Ismail, 2014). Dalam hal ini, menjadi perlu untuk dipahami lebih jauh tentang karakteristik anak digital native yang merupakan individu multitasker. Mereka dapat mempergunakan beberapa perangkat digital pada saat bersamaan. Mereka dapat menonton video, menjelajahi web, memainkan game online sambil chatting dengan temannya (Gentile, dkk., 2014).

Penelitian lain menunjukkan bahwa perangkat digital digunakan secara strategis sebagai alat pengasuhan anak (Levine, dkk., 2019) atau dukungan pendidikan (Chen, dkk., 2020). Karena itu, keterampilan fungsi eksekutif atau proses kognitif orang tua harus ditingkatkan seperti perhatian, kontrol impuls, dan koordinasi tugas, serta menilai konsumsi media oleh anak mereka (Zurcher dkk., 2020). Intensitas dan durasi menonton TV, menonton video, dan waktu layar media sosial yang tinggi dikaitkan dengan ukuran kognisi yang lebih rendah (Walsh dkk., 2020).
Dijelaskan oleh Ramasubramanian (2017), penggunaan layar harus dibatasi untuk mengurangi efek konten dan konteks negatif pada perkembangan anak. Dalam hal ini gaya pengasuhan digital dan karakteristik orang tua merupakan bentuk pencegahan yang sangat potensial (Konok, dkk., 2019).

Mediasi dalam penggunaan internet didukung oleh strategi orang tua, teknik dan praktik pengasuhan anak yang didasari oleh nilainilai dan sikap orangtua. Nilai-nilai tersebut dipengaruhi oleh dimensi budaya yang lebih luas dalam masyarakat tertentu seperti individualisme dan kolektivisme (Schwarz, dkk., 2005). Riset yang dilakukan oleh Kirwil (2009) mengidentifikasi adanya pengaruh lintas budaya dalam strategi mediasi orang tua terhadap penggunaan internet oleh anak-anak. Sebuah riset di Singapura mengungkapkan bahwa orang tua cenderung menggunakan strategi mediasi yang lebih sederhana untuk mengawasi dan mengontrol penggunaan teknologi digital anak mereka (Shin \& Li, 2016).

Mediasi orang tua yang juga disebut pemantauan media oleh orang tua (Padilla-Walker, dkk., 2012) melibatkan interaksi orang tua dengan anak-anak mereka tentang penggunaan media, termasuk restriktif, aktif, dan co-viewing atau menemani anak menonton konten digital. Teori mediasi menyatakan bahwa orang tua menggunakan strategi komunikasi interpersonal yang berbeda dalam upaya mereka untuk mengurangi efek negatif dari media dalam kehidupan anakanak mereka (Clark, 2011).

Strategi mediasi media yang diterapkan orang tua ketika anak mengakses perangkat digital, seperti televisi dan video game, terklasifikasikan dalam tiga jenis, yaitu restriktif, aktif, dan co-viewing (Koolstra \& Lucassen, 2004; Nikken \& Jansz, 2006). Mediasi restriktif melibatkan kontrol terhadap jumlah waktu yang dihabiskan anak-anak di media dan konten yang diizinkan untuk mereka akses. Mediasi aktif bersifat instruktif atau normatif, dan mencakup berbagi komentar kritis, termasuk penjelasan tentang konten yang kompleks. Terakhir, coviewing adalah mediasi dengan menonton atau bermain bersama anak.

Para peneliti telah memetakan berbagai praktik dan strategi mediasi yang diterapkan orang tua di lapangan berdasarkan jenis dan tingkat mediasinya. Lwin dkk (2008), mendeskripsikan penggabungan dua tipe mediasi dalam empat strategi orangtua: restriktif, promotif (instruktif), selektif (kombinasi dari keduanya), dan laissez faire (tidak ada mediasi sama sekali). Livingstone dan Helsper (2008) menemukan empat faktor mediasi orang tua, "co-viewing aktif" dan tiga jenis "mediasi restriktif". Co-use atau 
penggunaan bersama secara aktif mencakup interaksi instruktif dan berbagi pengalaman penggunaan Internet dengan duduk di samping anak. Adapun mediasi restriktif meliputi penggunaan teknis alat penyeleksi konten, pembuatan aturan (membatasi interaksi sosial daring), dan pemantauan aktif orang tua terhadap situs web yang dikunjungi dan pengecekan email.

Sementara penelitian tentang mediasi media pada anak secara umum telah banyak dilakukan, pada anak sekolah dasar (Borzekowski \& Robinson, 2007), usia 12-17 tahun (Livingstone \& Helsper, 2008), dan usia 6-17 tahun (Kirwil, 2009). Penelitian lain tentang mediasi media bagi anak yang dilakukan oleh Zaman dkk., (2016) menggunakan sampel usia 3-9 tahun, yang merupakan gabungan dari anak usia dini 3-6 tahun dan anak usia sekolah dasar 7-9 tahun. Akan tetapi, penelitian tersebut tidak ada satupun yang dilakukan pada masa pandemi, yang diasumsikan bahwa kondisi pandemi dapat merubah perilaku bermedia online pada anak. Penulis berargumen, bahwa mediasi media dan disiplin digital merupakan hal yang urgen untuk memastikan peningkatan kesan positif dan pencegahan dampak negatif dari konten internet, mengingat intensitas dan jangka waktu akses perangkat digital oleh anak usia dini yang meningkat pada masa pandemi COVID-19.

Pertanyaan yang diajukan dalam penelitian ini adalah bagaimana mediasi media dan disiplin digital yang diterapkan orang tua dalam penggunaan perangkat digital oleh anak usia dini pada masa work and study from home ini. Pada saat terjadi peningkatan akses perangkat digital oleh anak, implementasi mediasi media dan disiplin digital memegang peranan penting. Mediasi media bertujuan menjadikan penggunaan perangkat digital lebih bermanfaat, sedangkan disiplin digital dapat mengelola penggunaan perangkat tersebut agar tidak berlebihan.

\section{Metode Penelitian}

\section{Partisipan, desain, dan prosedur}

Penelitian ini dilakukan terhadap partisipan dengan karakteristik dosen di fakultas pendidikan; secara spesifik terkait dengan anak; mempunyai anak usia dini (2-8 tahun); berdomisili di wilayah yang memberlakukan Pembatasan Sosial Berskala Besar di masa pandemi COVID-19. Pembatasan karakteristik ini bertujuan untuk mengetahui apakah tingkat pendidikan tinggi orang tua berperan pada penerapan disiplin digital dan mediasi media terhadap anak mereka. Pada tahap awal penulis mengumpulkan tujuh orang subyek, untuk memperkuat saturasi data, penulis menambahkan jumlah subyek penelitian hingga mencapai 27 orang.

Penelitian ini merupakan studi kualitatif deskriptif. Pendekatan kualitatif dipilih untuk mendapatkan data secara mendalam terkait fenomena mediasi orang tua pada perilaku digital anak usia dini. Keabsahan data diperoleh melalui peningkatan ketekunan dalam penelitian dengan melakukan wawancara lanjutan. Pengumpulan data menitikberatkan pada wawancara terstruktur. Bentuk wawancara ini digunakan peneliti untuk meminimalkan variasi data sehingga analisis menjadi lebih sulit. Wawancara dilakukan secara daring melalui aplikasi Whatsapp dan Google Meet. Situasi pandemi yang mengharuskan physical distancing menjadi alasan utama penggunaan aplikasi tersebut dalam pengumpulan data. Jika data yang diberikan partisipan melalui Whatsapp kurang memadai, maka peneliti akan menghubungi mereka melalui Google Meet. Setiap partisipan dihubungi oleh peneliti sekitar 5-7 kali untuk mendapatkan data yang mendalam.

\section{Teknik analisis}

Analisa data dilakukan peneliti secara manual yang diawali dengan membuat verbatim hasil wawancara (Bungin, 2007), kemudian dilanjutkan membaca data berulang kali untuk menemukan tema dan katagorisasi jawaban wawancara. Pada tahap akhir, peneliti melakukan interpretasi data dan menarik kesimpulan.

\section{Hasil Penelitian}

Partisipan dalam penelitian ini memiliki karakteristik khusus yang mencerminkan individu dengan pendidikan tinggi. Karakteristik inilah yang menjadi konteks perilaku disiplin digital dan mediasi media yang diterapkan oleh partisipan kepada anak mereka dalam kondisi bekerja dan belajar dari rumah.

\section{Persepsi orang tua tentang disiplin digital pada anak}

Pilihan strategi disiplin digital orang tua tergantung pada ancaman konten yang diakses anak terhadap nilai-nilai yang mereka lestarikan. Semakin besar kemungkinan konten tersebut dapat menghancurkan nilai-nilai yang dipertahankan orang tua, maka mereka akan semakin ketat melakukan pembatasan. Dalam penelitian ini, seluruh partisipan mengakui bahwa disiplin digital sangat penting diterapkan bagi anak mereka yang masih berada dalam rentang usia dini.

Orang tua pada umumnya menyadari bahwa pada masa usia dini di mana anak mengalami perkembangan yang sangat pesat, 
perangkat digital dapat memberikan stimulasi namun juga dapat berdampak negatif bagi aspek perkembangan anak. Oleh karena itu, orang tua secara umum memandang bahwa disiplin dalam penggunaan perangkat digital oleh anak harus diterapkan. Seluruh partisipan mempersepsikan disiplin digital sebagai aturan-aturan yang ditetapkan orang tua saat anak mengakses perangkat digital.

Tabel 1

Data demografik partisipan

\begin{tabular}{llll}
\hline Variabel & Kategori & Frekuensi & Presentase \\
\hline Jenis Kelamin & Laki-laki & 12 & 44.44 \\
Usia & Perempuan & 15 & 55.56 \\
& $25-30$ & 9 & 33.33 \\
\multirow{2}{*}{ Tingkat Pendidikan } & $31-35$ & 15 & 55.56 \\
& $36-40$ & 3 & 11.11 \\
Latar Belakang Pendidikan & Magister & 26 & 96.29 \\
& Doktoral & 1 & 3.71 \\
& PGMI/PGSD & 14 & 51.85 \\
& PGRA/PGPAUD & 12 & 44.44 \\
\hline
\end{tabular}

Mayoritas partisipan (21) berpendapat bahwa disiplin digital bertujuan untuk mencegah kecanduan digital pada anak, sebagian lainnya (6 partisipan) mengungkapkan bahwa disiplin digital dapat mencegah dampak negatif dari konten yang diakses oleh anak.

Kondisi pandemi COVID-19 mengharuskan orang tua untuk membatasi ruang jelajah dan interaksi anak dengan teman sebaya. Anak tidak lagi bertemu dengan teman karena sekolah ditutup. Anak juga tidak bisa leluasa bermain bersama teman di sekitar rumah. Kondisi ini, diakui oleh orang tua, sangat cepat membuat anak bosan yang pada gilirannya menjadikan anak rewel. Orang tua menerapkan beberapa strategi untuk menenangkan anak dan membuat mereka mudah diatur. Mayoritas partisipan memanfaatkan perangkat digital sebagai upaya yang dinilai paling cepat untuk menenangkan anak ketika bosan, rewel atau membuat anak tenang di saat orang tua bekerja. Dalam hal ini, terdapat orang tua yang langsung memberikan perangkat digital, tetapi ada yang menjadikannya sebagai strategi terakhir, jika cara lain tidak berhasil.

\section{Strategi penerapan disiplin digital oleh orang tua}

Mayoritas partisipan (23 orang) mengakui adanya peningkatan intensitas akses perangkat digital yang dilakukan oleh anak selama masa pandemi COVID-19 ini. Peningkatan tersebut disebabkan karena minimnya aktivitas fisik yang dapat dilakukan oleh anak, terbatasnya interaksi dengan teman sebaya, dan banyaknya kesibukan yang harus dilakukan oleh orang tua selama bekerja dari rumah. Para partisipan memang sudah menerapkan disiplin digital, tetapi belum konsisten atau baru saja dimulai sejak melihat peningkatan akses perangkat digital oleh anak selama masa pandemi ini. Bahkan ada beberapa partisipan (2 orang) yang belum menerapkan aturan penggunaan perangkat digital oleh anak.

Sedangkan 4 partisipan lain menyatakan bahwa tidak ada peningkatan yang berarti dalam intensitas maupun durasi waktu akses perangkat digital oleh anak. Hal ini terjadi karena mereka memang telah menerapkan disiplin digital secara konsisten sejak lama, sebelum penyebaran COVID-19 melanda Kota Banjarmasin. Konsistensi penerapan disiplin digital tersebut dibangun atas dasar komunikasi yang baik dengan anak. Orang tua membuat kesepakatan dengan anak mereka sebelum menerapkan disiplin. Orang tua juga memberikan hadiah jika anak berhasil menjalankan disiplin yang disepakati dan memberikan hukuman jika anak melanggar.

Ada tiga macam pola disiplin yang diterapkan oleh orang tua, yaitu mengurangi, memitigasi dan kombinasi dari pola disiplin yang disebutkan terdahulu. Orang tua akan menerapkan disiplin yang bertujuan mengurangi penggunaan perangkat digital karena mereka menganggap intensitas dan durasi penggunaan melebihi batas yang wajar. Di sisi lain, orang tua akan menerapkan disiplin digital yang bertujuan memitigasi jika mereka merasa bahwa intensitas dan durasi akses perangkat digital oleh anak tidak berlebihan, jadi hanya diperlukan usaha untuk meminimalisir kemungkinan akses ke konten negatif. Sedangkan orang tua akan menerapkan pola kombinasi jika mereka merasa anak tidak bisa membatasi diri ketika menggunakan perangkat digital dan belum mampu menyaring konten yang layak dan tidak layak diakses. Anak-anak yang memerlukan penerapan disiplin digital pola kombinasi ini biasanya langsung meniru apa yang dilihatnya. Jika mereka melihat konten super hero yang 
melakukan perkelahian, mereka juga akan mencontoh jurus-jurus yang dilihat sambil pura-pura berkelahi.

Ada berbagai macam strategi penerapan disiplin yang diimplementasikan oleh partisipan untuk mengatur penggunaan perangkat digital oleh anak usia dini mereka. Seluruh partisipan mengakui menggunakan lebih dari satu strategi. Jenis strategi tersebut disesuaikan dengan kondisi psikologis dan kemampuan anak mengoperasikan perangkat digital. Orang tua menerapkan strategi berbeda terhadap anak yang mudah tantrum dan anak yang mudah mengalihkan perhatian. Selain itu, semakin bertambah usia dan bertambah keahlian dalam menggunakan perangkat digital, intensitas dan jangka waktu aksesnya pun semakin besar.

Strategi yang paling popular bagi partisipan adalah strategi pengalihan, yaitu ketika anak ingin menggunakan perangkat digital, orang tua menawarkan kepada mereka kegiatan lain, seperti bermain, mewarna atau membacakan dongeng. Strategi ini, menurut para partisipan, cukup efektif untuk menunda bahkan menjadikan anak lupa akan keinginannya mempergunakan perangkat digital.

\section{"Saya sangat terbantu dengan keberadaan anak pertama yang bisa memberi pengaruh kepada kegiatan adik-adiknya. Ia sangat aktif secara fisik sehingga ia sering mengajak orang tua dan adik-adiknya bermain badminton, lari di depan rumah atau berkeliling komplek dengan sepeda." (P 23)}

Selain strategi pengalihan, ada banyak partisipan yang menerapkan strategi pembatasan, yaitu membatasi durasi atau situasi yang diperbolehkan bagi anak untuk mengakses perangkat digital. Dengan membatasi durasi atau situasi ini, orang tua tidak perlu berkonfrontasi langsung dengan anak. Strategi ini membuat anak mendapatkan keinginannya dan orang tua tetap memiliki kontrol terhadap akses perangkat digital anak.

Strategi lain yang juga sering dilakukan partisipan adalah penghambatan, yaitu membuat anak tidak bisa mengakses perangkat digital, seperti mematikan sambungan internet pada smartphone, mengunci smartphone dengan kode rahasia, melepaskan kabel antenna atau menyembunyikan remote televisi.

"Saya mengunduh beberapa video dan mematikan sinyal ketika anak menggunakan smartphone. Mungkin karena yang ditonton itu-itu saja, ia jadi bosan." (P 08)

"Biasanya saya lepas saluran TV kabelnya. Kalau ga ada sinyal kayak gitu, anak hanya tahu pemancarnya rusak." (P 15)

Enam orang partisipan lain (P 01, 02, 04, 17,22 , dan 25) menyatakan bahwa mereka menerapkan strategi pembiasaan. Mereka menanamkan kebiasaan kepada anaknya agar mengakses smartphone maupun laptop hanya ketika orang tuanya ada. Mereka malah tidak menggunakan smartphone atau laptop ketika orang tua bekerja. Jika mereka ingin menggunakan perangkat digital, biasanya akan meminta izin terlebih dahulu. Karena sudah terbiasa dengan disiplin ini, anak jarang sekali merengek atau bahkan sampai menangis saat ingin meminjam smartphone.

"Saya kadang nonton Youtube bersama. Tapi lebih banyak saya carikan video anak terus dia nontonnya di tempatyang bisa saya pantau." (P 10)

\section{Mediasi media aktif dan restristif}

Terkait mediasi media, mayoritas partisipan (24 orang) tidak familiar dengan istilah ini. Beberapa orang tua ( 3 orang) memahami mediasi media sebagai upaya orang tua menerjemahkan konten yang diakses anak. Minimnya pemahaman subyek terhadap mediasi media menyebabkan mereka tidak mengetahui urgensi dari kegiatan tersebut. Meskipun demikian pada wawancara lanjutan mereka telah dapat menjelaskan bahwa mediasi media tidak kalah penting dari disiplin digital dan sebagian dari mereka bahkan sudah menerapkannya.

Terdapat dua jenis mediasi utama yang biasanya dilakukan oleh orang tua. Mediasi yang paling sering diterapkan adalah mediasi restriktif, yang ditinjukkan pada penerapan seperangkat aturan dalam penggunaan perangkat digital oleh anak. Aturan-aturan tersebut biasanya terkait dengan tempat, waktu, tipe konten, dan sikap dalam penggunaan perangkat digital. Jenis mediasi kedua adalah mediasi aktif. Mediasi ini yang paling jarang dilakukan oleh karena mayoritas partisipan memiliki kesibukan yang padat. Selain itu, minimnya literasi partisipan mengenai mediasi media membuat mereka merasa kurang memahami besarnya manfaat dari mediasi ini. Pemikiran partisipan yang menerapkan mediasi media masih terbatas bagaimana mengenalkan anak dengan perangkat digital sembari menghindarkan mereka dari kecanduan. Mayoritas partisipan belum berpikir untuk membangun 
literasi digital anak mereka. Literasi digital ini dapat tumbuh melalui komunikasi aktif dan positif orang tua dengan anak ketika mereka menggunakan perangkat digital.

Hambatan utama yang dirasakan oleh partisipan untuk melakukan mediasi aktif adalah waktu. Mediasi ini mengharuskan mereka memiliki waktu luang untuk menemani anak mengakses perangkat digital. Selain itu, partisipan juga harus telaten memberikan penguatan terhadap konten positif yang ditonton anak dan melakukan upaya preventif agar anak tidak mengakses konten negatif. Jika anak terpapar konten yang kurang pantas, seperti adegan perkelahian, maka orang tua perlu mengajak anak berdiskusi mengenai dampak buruk adegan tersebut dan memberikan peringatan agar anak tidak menirunya.

Tabel 2

Mediasi media dari orang tua

\begin{tabular}{lll}
\hline Partisipan & Tipe mediasi & Bentuk Mediasi \\
\hline $03,05,06,09,11,13,15$, & Restriktif & Menetapkan jadwal akses, membatasi durasi, \\
$16,18,19,21,24,26$ & & membatasi konten
\end{tabular}

07, 10, 23, 14, $27 \quad$ Restriktif; co-viewing

Membatasi durasi dan konten, menonton bersama, memantau konten yang ditonton anak dari jauh

02, 04, 08, $20 \quad$ Teknikal; Aktif

Menginstal atau mengatur filtering, mengajak anak diskusi saat menonton konten

01, 12, 17, 22, $25 \quad$ Restriktif; Aktif

Membatasi jadwal, durasi dan konten, mereview konten yang sudah ditonton bersama

Selain didasari oleh pengetahuan dan kesadaran akan pentingnya mediasi aktif dalam mengembangkan berpikir kritis, jenis mediasi ini mulai diterapkan orang tua setelah melihat timbulnya dampak negatif perangkat digital pada anak. Beberapa dampak negatif tersebut antara lain anak mulai sulit diatur dalam menggunakan perangkat digital dan menunjukkan perilaku resisten bahkan agresif saat dilarang menggunakan perangkat digital. Dalam proses mediasi aktif ini, orang tua juga mengajak anak berdiskusi tentang dampak buruk akses berlebihan atas perangkat digital dengan tujuan mengurasi intensitas atau durasi waktu yang mereka habiskan dalam menggunakan perangkat digital tersebut.

"Kami berdua sama-sama ngajar. Jadi anak, saya yang bawa. Kalau sudah jadwal ngajar, saya kasih HP biar tenang. Namun kelamaan malah nagih terus. Sulit diminta berhenti. Baru kami sadar perlunya komunikasi intens dengan anak pentingnya disiplin digital dan bahaya kecanduan." (P 07)

"Sekarang kalau anak pegang HP, harus ada yang mendampingi. Paling tidak untuk memantau konten yang diakses dan durasi waktunya. Biasanya juga tanya-tanya tentang cerita video yang ditonton. Nanti nilai-nilai positif kontennya diingatkan lagi dengan anak. Misalnya, tadi kaka sudah lihat kan di video, kalau gak sikat gigi sebelum tidur, nanti giginya dicangkul sama kuman jadi berlobang. Mau deh kaka sikat gigi." (P 25)

Sebagai langkah protektif, orang tua menggunakan beberapa pengaturan khusus seperti Youtube Kids dan filter safe search. Di antara mereka juga ada yang memasang aplikasi Google Family Link. Langkah-langkah yang dilakukan oleh orang tua ini termasuk dalam mediasi teknikal.

"Kalau mediasi restriktif saja seperti-
nya tidak cukup. Mediasi aktif juga
sudah dilakukan, namun kayaknya
perlu banyak waktu. Sedangkan ayah
dan ibunya bekerja. Jadi kami aktif-
kan youtube kids agar konten video
yang ditonton anak saya aman."
(P 20).

\section{Diskusi}

Penelitian ini mengungkapkan bahwa disiplin digital memang identik dengan mediasi restriktif, tetapi dengan beberapa perbedaan. Disiplin digital mengharuskan adanya iklim keluarga yang mendukung penerapan disiplin. Ketika orang tua menuntut kepada anak untuk membatasi penggunaan perangkat digital, mereka harus terlebih 
dahulu menata kebiasaan penggunaan perangkat digital mereka seperti tidak meletakkan smartphone sembarangan, tidak menggunakan smartphone ketika bermain bersama anak, dan tidak menggunakan perangkat digital pada waktu dan situasi tertentu. Adapun mediasi restriktif hanya ditampilkan dalam sejumlah aturan akses perangkat yang harus diterapkan oleh anak, tanpa adanya iklim yang mendukung. Ketika usia anak semakin bertambah dan daya jelajah digitalnya semakin luas, maka semakin besar kemungkinan mereka menunjukkan sikap resisten atau agresif. Kuatnya iklim pendukung yang dibangun oleh orang tua dapat meminimalisir sikap resisten ini.

Temuan dari studi ini memperkuat hasil dari studi yang dilakukan oleh Nikken (2017), dimana penggunaan perangkat digital oleh orang tua menjadi prediktor penting dalam konsumsi perangkat digital oleh anak-anak. Studi ini mengungkapkan bahwa persepsi orang tua dan strategi disiplin digital yang diterapkan pada anak berperan dalam menjelaskan perilaku digital anak.

Kesadaran orang tua terhadap dampak negatif penggunaan media pada anak usia dini, seperti dijelaskan Cingel \& Krcmar (2013), yaitu kebiasaan penggunaan perangkat digital pada anak yang terlalu dini, akan beresiko menjadikan anak pengguna media yang tinggi hingga ia dewasa, mengarahkan orang tua untuk terlibat dalam mediasi media baik secara aktif maupun restriktif.

Dalam hal ini, orang tua menghadapi tantangan yang besar dalam mengelola disiplin dan mediasi dalam praktik penggunaan perangkat digital oleh anak. Mereka dikenal sebagai digital native, yaitu generasi yang lahir, tumbuh dan berkembang dalam dunia digital. Generasi ini memiliki kecerdasan teknologi, kepercayaan diri akan keterampilan digital, dan mempunyai pemahaman yang seringnya lebih baik tentang teknologi digital dibanding orang tuanya (Tufte \& Rasmussen, 2010). Tantangan tersebut menjadi lebih besar ketika pandemi COVID-19 melanda. Para orang tua harus bekerja dari rumah sekaligus menemani anak belajar. Kesibukan orang tua dalam kegiatan rumah tangga dan tugas profesi, kecemasan dalam menghadapi pandemi, dan masalah ekonomi yang semakin memburuk menjadikan mereka lalai dalam mengatur disiplin dan mediasi media ketika anak menggunakan perangkat digital. Malah orang tua cenderung memanfaatkan perangkat digital untuk mengasuh anak (Pratiwi, 2020).

Situasi tersebut juga dihadapi oleh kelompok orang tua dengan latar pendidikan tinggi dan memiliki sumber daya lebih dalam mengelola pengasuhan anak, termasuk penerapan mediasi media dan disiplin digital. Ketika menghadapi tantangan dalam pekerjaan seperti tuntutan yang besar, stress dan kendala waktu, pendidikan yang dimiliki orang tua terbukti memberikan keterampilan dan sumber daya individu yang memungkinkan mereka untuk mengatasi tantangan tersebut. Dalam hal ini seperti dijelaskan oleh Duncan dan Magnuson (2003), orang tua yang berpendidikan tinggi lebih cenderung menghargai proses self-direction sehingga cenderung menerapkan praktik pengasuhan yang menekankan otonomi.

Pendidikan orang tua adalah salah satu prediktor terkuat bagi perkembangan akademik anak. Orang tua yang berpendidikan tinggi lebih sering terlibat dalam praktik pengasuhan yang dapat meningkatkan perkembangan kognitif anak di kemudian hari (Harding, dkk., 2017). Di sisi lain, Pendidikan tinggi juga memiliki konsekuensi pada tuntutan pekerjaan yang biasanya memiliki tekanan yang lebih tinggi, ditambah rutinitas keseharian dapat menciptakan stres, khususnya di pagi hari dan menjelang tidur malam (Nockolds, 2016). Stres tanpa dukungan yang kuat dapat mengakibatkan orang tua melalaikan pengasuhan anaknya. Kesibukan orang tua dalam bekerja berdampak pada berkurangnya waktu yang disediakan mereka untuk anak (Sari, 2020). Hal ini juga dialami oleh kelompok partisipan dalam studi ini yang rata-rata berpendidikan tinggi dan menjelaskan kondisi kesibukan serta tekanan pekerjaan sebagai alasan memilih mediasi restriksi dibandingkan aktif.

Penelitian ini mengungkap bahwa mayoritas responden memilih untuk mengurangi interaksi anaknya dengan perangkat digital daripada memitigasi konten negatif yang mungkin mereka temukan saat mengakses perangkat digital tersebut. Pilihan ini dikarenakan orang tua tidak memiliki cukup waktu untuk menemani anak saat menggunakan perangkat digital. Orang tua memiliki kesibukan lain seperti mengerjakan tugas rumah tangga, mengajar, hingga mengurus bisnis online. Selain itu, pilihan untuk memitigasi mengharuskan orang tua mampu menjalin komunikasi positif dengan anak. Orang tua harus memiliki banyak pengetahuan tentang media digital dan segala dampaknya, kemudian menjelaskannya dengan bahasa yang mudah dicerna oleh anak. Komunikasi dan perilaku penggunaan perangkat digital oleh orangtua memegang peran kunci yang menentukan keberhasilan penerapan disiplin akses perangkat digital oleh anak. Studi yang dilakukan Nathanson (2010) menjelaskan bahwa mediasi orang tua dari media anak-anak sering menjadi faktor kunci dalam efek potensial dari konten negatif, seperti memperbaiki dampak kekerasan atau mengatasi stereotip gender.

Penelitian ini juga mengungkapkan bahwa jenis mediasi media yang diterapkan orang tua bersifat dinamis. Mediasi dapat berubah dan 
dilakukan lebih kompleks dengan kombinasi mediasi lainnya, seiring bertambahnya pengetahuan orang tua, tersedianya waktu untuk mediasi dan kesadaran bahwa jenis mediasi yang ada tidak cukup untuk menghindarkan anak dari dampak negatif paparan digital. Partisipan yang menerapkan mediasi restriktif pun pada dasarnya mengakui bahwa mereka memerlukan kombinasi mediasi aktif untuk membendung kecanduan digital, sikap resisten anak, atau dengan maksud membangun literasi digital. Namun, mereka menyatakan tidak memiliki waktu yang banyak untuk melakukan kombinasi mediasi tersebut.

Mediasi orang tua dan paparan media adalah dua faktor yang menentukan sikap anak. Menurut Jennifer dan Nathanson (2008), media sebagai agen sosialisasi, sedangkan menurut Hogan (2012), mediasi dari orang tua dapat memengaruhi sikap, kepercayaan, dan perilaku anakanak. Hal ini senada dengan studi yang dilakukan Collier (2016) tentang bagaimana mediasi media memengaruhi sikap anak. Orang tua memiliki kemampuan untuk mengurangi beberapa efek buruk dari media dengan menggunakan strategi mediasi tertentu.

Fisch (2017) mengemukakan bahwa mediasi media dapat dilakukan sebelum, ketika dan sesudah anak menggunakan perangkat digital. Sebelum penggunaan perangkat digital, orang tua dapat memberi review terhadap suatu konten positif atau memberi peringatan dampak buruk atas konten negatif. Ketika penggunaan perangkat digital sedang berlangsung, orang tua dapat memberikan komentar atau pertanyaan yang mengundang reaksi berpikir kritis. Mediasi yang dapat dilakukan oleh orang tua setelah anak selesai menggunakan perangkat digital adalah dengan terlibat dalam diskusi tindak lanjut untuk memperkuat pelajaran yang dipetik dan mengaplikasikannya pada tindakan nyata. Namun jika konten itu ternyata memiliki nilai negatif, maka orang tua harus segera mendiskusikannya dengan anak untuk melawan konten yang tidak menyenangkan itu. Radanielina-Hita (2015) menemukan bahwa kritik orang tua terhadap konten media menyebabkan pemikiran kritis anaknya juga lebih meningkat. Selain itu, Nikkelen, dkk (2016) menyatakan mediasi media orang tua berperan besar dalam menangkal konten keke-rasan dari media yang diakses anak ADHD.

Mediasi orang tua juga terkait dengan peningkatan agresi relasional (Rasmussen, dkk., 2017). Valkenburg dan Peter (2013) menjelaskan bahwa ketika orang tua menerapkan gaya pengasuhan yang dianggap oleh anak sebagai ancaman terhadap independensi mereka, ini akan menimbulkan reaktansi. Reaktansi, pada gilirannya, meningkatkan kemungkinan perlawanan dari anak sehingga menimbulkan efek bumerang. Berdasarkan konsep reaktansi ini, mediasi orang tua dianggap tidak efektif ketika orang tua mencoba untuk memaksakan aturan dan pendapat mereka pada anak mereka, yaitu menggunakan mediasi restriktif. Mediasi yang tidak konsisten juga mengakibatkan reaksi kontra-efektif, dan memicu reaktansi. Sebaliknya, mediasi orang tua dianggap efektif ketika dilakukan dengan cara yang mendukung otonomi, sehingga anak-anak merasa pendapatnya dihargai (Joussemet, dkk., 2008). Valkenburg dan Peter (2013) menyajikan beberapa temuan yang mendukung argumen bahwa hal yang penting bagi orang tua adalah bagaimana cara mereka terlibat dalam mediasi anaknya. Mediasi restriktif dan mediasi tidak konsisten berpengaruh besar menimbulkan perilaku yang tidak menguntungkan (konflik dan agresi keluarga), sedangkan mediasi dengan mendukung otonomi anak dalam mengakses perangkat digital secara negatif dikaitkan dengan perilaku ini. Konsep ini mungkin lebih mengena jika diterapkan pada anak yang lebih dewasa, seiring meningkatkan kemampuan mereka dalam mengoperasikan perangkat digital dan tingginya intensitas interasi mereka, baik untuk pembelajaran, sosial atau hiburan.

Terdapat dua poin utama dari hasil studi yang ditandai mediasi restriktif dalam pengalaman digital anak. Pembatasan waktu dalam mengkases perangkat digital meminimalisir bahaya bagi perkembangan fisik (Cain \& Gradisar, 2010). Selain itu, mediasi restriktif dapat mencegah anak dari mengakses konten yang memuat materi kekerasan dan seksual (Bushman \& Anderson, 2009).

Dari data yang telah dipaparkan, mediasi aktif yang dilakukan dengan membahas konten media secara terbuka bersama anak-anak dapat meningkatkan keterampilan berpikir kritis tentang konten yang dikonsumsi. Mediasi aktif dapat menumbuhkan kesadaran diri anak untuk melindungi diri dari paparan konten negatif. Namun, mediasi jenis ini tidak memiliki kekuatan signifikan dalam membatasi waktu interaksi anak dengan perangkat digital (Kerr, dkk., 2010).

Orang tua dapat menggunakan mediasi aktif sebagai tambahan terhadap aturan mediasi restriktif yang mereka miliki sebelumnya. Kombinasi dua pola mediasi ini mungkin paling efektif (Gentile, dkk., 2014). Seperti yang disarankan oleh (Sonc, dkk., 2013), semakin banyak aktivitas digital dalam mediasi media yang dilakukan orang tua, mereka akan semakin memahami masalah yang mungkin dihadapi anak mereka saat menggunakan teknologi digital. 


\section{Kesimpulan}

Pola disiplin digital yang ditemukan ada 3 macam, yaitu: mengurangi intensitas dan durasi akses perangkat digital, memitigasi konten, dan mengombinasi keduanya. Pola disiplin tersebut dilakukan dengan beberapa strategi, yaitu: pengalihan aktivitas ketika anak ingin mengakses perangkat digital dengan menawarkan beberapa kegiatan lain, pembatasan durasi atau situasi yang diperbolehkan bagi anak untuk mengakses perangkat digital, penghambatan akses (seperti mematikan sambungan internet pada smartphone, mengunci smartphone dengan kode rahasia, melepaskan kabel antenna atau menyembunyikan remote tv), serta pembiasaan untuk menggunakan perangkat digital jika sudah mendapat izin orang tua.

Mayoritas partisipan belum mengenal istilah mediasi media, namun pada aplikasinya, yang paling banyak dan sering diterapkan oleh partisipan adalah tipe mediasi restriktif. Selain itu, ada juga yang mengombinasikan berbagai tipe mediasi, yaitu restriktif dan co-viewing, teknikal dan aktif;, serta restriktif dan aktif.

\section{Daftar Pustaka}

Attrill, A., \& Fullwood, C. (2016). Applied cyberpsychology. Practical Applications of Cyberpsychological Theory and Research. Palgrave Macmillan.

Borzekowski, D. L. G., \& Robinson, T. N. (2007). Conversations, Control, and Couch-Time. Journal of Children and Media, 1(2), 162176.

https://doi.org/10.1080/174827907013 39183

Bungin, B. (2007). Penelitian kualitatif: Komunikasi, ekonomi, kebijakan publik, dan ilmu sosial lainnya (Vol. 2). Prenada Media Group.

Bushman, B. J., \& Anderson, C. A. (2009). Comfortably numb: Desensitizing effects of violent media on helping others. Psychological Science, 20(3), 273-277. https://doi.org/10.1111/j.14679280.2009.02287.x

Cain, N., \& Gradisar, M. (2010). Electronic media use and sleep in school-aged children and adolescents: A review. Sleep Medicine, 11(8), 735-742. https://doi.org/10.1016/j.sleep.2010.02. 006

Chen, C., Chen, S., Wen, P., \& Snow, C. E. (2020). Are screen devices soothing children or soothing parents? Investigating the relationships among children's exposure to different types of screen media, parental efficacy and home literacy practices. Computers in Human Behavior, 106462.

https://doi.org/10.1016/j.chb.2020.1064 62

Cingel, D. P., \& Krcmar, M. (2013). Predicting Media Use in Very Young Children: The Role of Demographics and Parent Attitudes. Communication Studies, 64(4), 374-394.

https://doi.org/10.1080/10510974.2013 .770408

Clark, L. S. (2011). Parental mediation theory for the digital age. Communication Theory, 21(4), 323-343. https://doi.org/10.1111/j.14682885.2011.01391.x

Collier, K. M., Coyne, S. M., Rasmussen, E. E., Hawkins, A. J., Padilla-Walker, L. M., Erickson, S. E., \& Memmott-Elison, M. K. (2016). Does parental mediation of media influence child outcomes? A meta-analysis on media time, aggression, substance use, and sexual behavior. Developmental Psychology, 52(5), 798-812. https://doi.org/10.1037/dev0000108

Duncan, G. J., \& Magnuson, K. A. (2003). Off with Hollingshead: Socioeconomic resources, parenting, and child development. Socioeconomic Status, Parenting, and Child Development, 83-106.

Fisch, S. M. (2017). Parental Mediation in an Evolving Media LandscapeCommonalities, Contrasts, and Implications for Design. In Media Exposure During Infancy and Early Childhood (pp. 221-225).

Gentile, D. A., Reimer, R. A., Nathanson, A. I., Walsh, D. A., \& Eisenmann, J. C. (2014). Protective effects of parental monitoring of children's media use a prospective study. JAMA Pediatrics, 168(5), 479-484. https://doi.org/10.1001/jamapediatrics. 2014.146

Harding, J. F., Morris, P. A., \& Hill, J. (2017). Understanding associations between lowincome mothers' participation in education and parenting. Journal of Research on Educational Effectiveness, 10(4), 704-731.

Hogan, M. J. (2012). Parents and other adults: Models and monitors of healthy media habits. In Handbook of children and the media (pp. 661-680).

Jennifer, L. C., \& Nathanson, A. I. (2008). Parent and School Interventions: Mediation and Media Literacy. In The Handbook of Children, Media, and Development (pp. 552-576). 
Joussemet, M., Landry, R., \& Koestner, R. (2008). A self-determination theory perspective on parenting. Canadian Psychology, 49, 194-200.

Kerr, M., Stattin, H., \& Burk, W. J. (2010). A reinterpretation of parental monitoring in longitudinal perspective. Journal of Research on Adolescence, 20(1), 39-64. https://doi.org/10.1111/j.15327795.2009.00623.x

Kirwil, L. (2009). Parental Mediation Of Children's Internet Use In Different European Countries. Journal of Children and Media, 3(4), 394-409. https://doi.org/10.1080/174827909032 33440

Konok, V., Bunford, N., \& Miklósi, Á. (2019). Associations between child mobile use and digital parenting style in Hungarian families. Journal of Children and Media, 14(1), 1-19. https://doi.org/10.1080/17482798.2019 .1684332

Koolstra, C. M., \& Lucassen, N. (2004). Viewing Behaviour of Children and TV Guidance by Parents: A Comparison of Parent and Child Reports. Communications, 29(2), 179-198.

Krcmar, M., \& Cingel, D. (2015). Examining two models of parent mediation of adolescent social media use. Journal of Family Communication, 16(3).

Lauricella, A. R., Wartella, E., \& Rideout, V. J. (2015). Young children's screen time: The complex role of parent and child factors. Journal of Applied Developmental Psychology, 36, 11-17.

Lee, S., \& Chae, Y. (2007). Children's Internet Use in a Family Context: Influence. 10(5), 640644.

https://doi.org/10.1089/cpb.2007.9975

Levine, L. E., Waite, B. M., Bowman, L. L., \& Kachinsky, K. (2019). Computers in Human Behavior Mobile media use by infants and toddlers. Computers in Human Behavior, 94(September 2018), 92-99. https://doi.org/10.1016/j.chb.2018.12.0 45

Livingstone, S., \& Helsper, E. J. (2008). Parental mediation of children's internet use. Journal of Broadcasting and Electronic Media, 52(4), 581-599. https://doi.org/10.1080/088381508024 37396

Lwin, M., STANALAND, A., \& MIYAZAKI, A. (2008). Protecting children's privacy online: How parental mediation strategies affect website safeguard effectiveness. Journal of Retailing, 84(2), 205-217. https://doi.org/10.1016/j.jretai.2008.04. 004

Nathanson, A. I. (2010). Using Television Mediation to Stimulate Nontraditional Gender Roles among Caucasian and African American Children in the US. Journal of Children and Media, 4(2), 174190.

https://doi.org/10.1080/174827910036 29644

Nikkelen, S., Vossen, H., Piotrowski, J., \& Valkenburg, P. (2016). Media Violence and Adolescents' ADHD-Related Behaviors: The Role of Parental Mediation. Journal of Broadcasting \& Electronic Media, 60(4), 657-675.

Nikken, P, \& Jansz, J. (2006). Parental Mediation of Children's Videogame Playing: A Comparison of the Reports by Parents and Children. Learning, Media and Technology, 31(2), 181-202.

Nikken, Peter. (2017). Implications of low or high media use among parents for young children ' s media use. Cyberpsychology, 11(3).

Nockolds, D. (2016). Acceleration for working sole parents: Squeezed between institutional temporalities and routinised parenting practices. Time \& Society, 25(3), 513-532.

Ofcom. (2014). The Communications Market Report.

http://stakeholders.ofcom.org.uk/binarie s/research/cmr/cmr14/2014_UK_CMR.p df

Padilla-Walker, L. M., Coyne, S. M., Fraser, A. M., Dyer, W. J., \& Yorgason, J. B. (2012). Parents and adolescents growing up in the digital age: Latent growth curve analysis of proactive media monitoring. Journal of Adolescence, 35, 1153-1165.

Pratiwi, H. (2020). Screen Time dalam Perilaku Pengasuhan Gererasi Alpha pada Masa Tanggap Darurat Covid-19. Jurnal Obsesi : Jurnal Pendidikan Anak Usia Dini, 5(1), 265.

https://doi.org/10.31004/obsesi.v5i1.54 4

Radanielina-Hita, M. L. (2015). Parental Mediation of Media Messages Does Matter: More Interaction About Objectionable Content Is Associated With Emerging Adults' Sexual Attitudes and Behaviors. Health Communication, 30(8), 784-798. https://doi.org/10.1080/10410236.2014 .900527

Ramasubramanian, S. (2017). Media exposure during infancy and early childhood: The effects of content and context on learning 
and development. Journal of Children and Media, 11(4), 502-503. https://doi.org/10.1080/17482798.2017 .1375216

Rasmussen, E. E., Coyne, S. M., Martins, N., Densley, R. L., Rasmussen, E. E., Coyne, S. M., Martins, N., \& Densley, R. L. (2017). Parental mediation of US youths , exposure to televised relational aggression. Journal of Children and Media, 12(2), 1-19. https://doi.org/10.1080/17482798.2017 .1405829

Rideout, V. J. (2013). Zero to Eight: Children's Media Use in America 2013. Common Sense Media.

Sari, M. (2020). Father Involvement in Early Childcare: Review of the literature. 2(1), 1136-1140.

Schwarz, B., Schafermeier, E., \& Trommsdorff, G. (2005). Relations between Value Orientation, Child-Rearing Goals, and Parenting: A Comparison of German and South Korean Mothers 1. 203-230.

Shin, W., \& Ismail, N. (2014). Exploring the role of parents and peers in young adolescents' risk taking on social networking sites. Cyberpsychology, Behavior, and Social Networking, 17(9), 578-583. https://doi.org/10.1089/cyber.2014.009 5

Shin, W., \& Li, B. (2016). Parental mediation of children' $s$ digital technology use in Singapore. Journal of Children and Media, 11(1).

https://doi.org/10.1080/17482798.2016 .1203807

Society, C. P. (2017). Screen time and young children: Promoting health and development in a digital world. Paediatrics \& Child Health, October, 461-468. https://doi.org/10.1093/pch/pxx123

Sonck, N., Nikken, P., \& de Haan, J. (2013). Determinants of Internet Mediation: Journal of Children and Media, 7(1), 96113.

https://doi.org/10.1080/17482798.2012 .739806
Sweetser, P., Johnson, D., Ozdowska, A., \& Wyeth, P. (2012). Active versus passive screen time for young children. Australian Journal of Early Childhood, 37(4), 94-98. https://doi.org/10.1177/183693911203 700413

Tufte, B., \& Rasmussen, J. (2010). Understanding Children as Consumers. In Children and the Internet. Sage.

Unantenne, N. (2014). Mobile Device Usage Among Young Kids: A South Asia Study. The Asian Parent Insight. https://s3-apsoutheast-1.amazonaws.com/tapsgmedia/theAsianparent+Insights+Devic $\mathrm{e}+$ Usage $+\mathrm{A}+$ Southeast + Asia + Study + Nove mber+20\%0A14.pdf\%0A

Valkenburg, P. M., \& Peter, J. (2013). The differential susceptibility to media effects model. Journal of Communication, 63(2), 221-243. https://doi.org/10.1111/jcom.12024

Walsh, J. J., Barnes, J. D., Tremblay, M. S., \& Chaput, J. P. (2020). Associations between duration and type of electronic screen use and cognition in US children. Computers in Human Behavior, 108(February), 106312. https://doi.org/10.1016/j.chb.2020.1063 12

Wartella, E., Lauricella, A. R., Rideout, V. J., \& Connell, S. (2013). PARENTING IN THE AGE OF DIGITAL TECHNOLOGY.

Zaman, B., Nouwen, M., Vanattenhoven, J., de Ferrerre, E., \& Looy, J. Van. (2016). A Qualitative Inquiry into the Contextualized Parental Mediation Practices of Young Children's Digital Media Use at Home. Journal of Broadcasting and Electronic Media, 60(1), $1-22$. https://doi.org/10.1080/08838151.2015 .1127240

Zurcher, J. D., King, J., Callister, M., Coyne, S., \& Stockdale, L. (2020). "I can multitask": The mediating role of media consumption on executive function's relationship to technoference attitudes. Computers in Human Behavior, 113, 106498. https://doi.org/10.1016/j.chb.2020.1064 98 